\title{
Arduino-based prototype to estimate heat stress indices in urban environments
}

\author{
Carlos Vargas-Salgado ${ }^{1}$, Lina Montuori ${ }^{2}$, Paula Bastida-Molina ${ }^{1}$, David Alfonso- \\ Solar ${ }^{2}$ \\ ${ }^{1}$ Department of electrical Engineering, Universitat Politecnica de Valencia, Spain, \\ ${ }^{2}$ Department of Applied Thermodynamics, Universitat Politecnica de Valencia, Spain.
}

\begin{abstract}
Thermal comfort indices are normally used for assessing and controlling heat stress conditions in both indoors and outdoors environment. In this paper, the results of the design and test of an Arduino-base prototype for estimating heat stress index is presented. This prototype allows the accurate detection of wind speed, air temperature, relative humidity, precipitation, atmospheric pressure, irradiation and globe thermometer temperature. By means of these parameters, it is possible to obtain indices such as mean radiant temperature (MRT) and wet bulb globe temperature (WBGT). As a result, the indices are estimated, stored in a database and analyzed. These values will be used in the future to measure the mitigation of heat stress in urban environments, by means of the construction of green facades, green roof or tree planting.
\end{abstract}

Keywords: Arduino; Heat stress index; globe temperature; WBGT; MRT. 


\section{Introduction}

Exposure to high-temperature environments can deviate in physical and psychological health problems (Deschenes, 2014), therefore, evaluating the relation between high temperature and health problems is an important task (Enander \& Hygge, 1990; Fishman, Carrillo, \& Russ, 2019; Gasparrini et al., 2017), even for urban planning (Gunawardena, Wells, \& Kershaw, 2017). However, in general terms, assessing heat stress index is not an easy task due to environmental changing conditions depend on de location, and therefore, a standardized heat stress index monitor is required for the location to asses (Maurya, Haque, Kumar, \& Diwakar, 2019). (V. H. Nguyen, Q. T. Tran, and Y. Besanger 2016).

On the other hand, several papers mentioned the use Arduino board as a monitoring system (A. D. Deshmukh and U. B. Shinde 2016, S. Ferdoush and X. Li 2014). The development of a low-cost SCADA system using an Arduino board is presented in (I. Allafi and T. Iqbal, 2018), where environmental variables and power generation from the photovoltaic system are measured. (J. L. Sarinda, T. Iqbal, and G. Mann 2017) presents the development of a system for remote wireless control and monitoring for a single power inverter. The hardware used by the authors includes an Arduino and a Raspberry development board.

This work presents and analyses the results of the design, commissioning and test of a prototype to measure continuously the parameter required to calculate MRT and WBGT for the purpose of carrying out actions to mitigate the heat stress.

\section{Methodology}

To measure parameters required for calculating heat stress indices, a low-cost heat stress monitor indices have been designed, built, commissioning and tested. The components used to set up the prototype are shown in table 1:

Table 1: Components used to set up the prototype

\begin{tabular}{|l|c|l|}
\hline \multicolumn{1}{|c|}{ Component } & Qty & \multicolumn{1}{|c|}{ Function } \\
\hline Arduino Mega & 1 & Microcontroller \\
\hline DTH22 & 1 & Relative humidity and Temperature sensor \\
\hline DS18B20 & 3 & Temperature sensor \\
\hline JL-FS2 & 1 & Cups anemometer 0-5 Vols \\
\hline BME280 & 1 & Pressure sensor \\
\hline LCD2004 + LCN1602 & 1 & Display \\
\hline TPL5110 & 1 & Timer \\
\hline
\end{tabular}




\begin{tabular}{|l|c|l|}
\hline RTC DS1307 & 1 & Real-time clock I2C \\
\hline INA219 & 3 & DC voltage and current sensor \\
\hline INA3221 & 1 & DC voltage and current sensor (Three-in-one sensor) \\
\hline MH-RD & 1 & Rain sensor \\
\hline C-0121 Cebek & 1 & PV Cell calibrated - Irradiation sensor \\
\hline CNC 165x135 6 V & 1 & PV solar panel \\
\hline DC-DC 5 V to 12 V & 1 & Boost converter 5 V to 12 V \\
\hline DC-DC 2.5- 5 V to 5 V & 1 & $2.5-5$ V to 5 V \\
\hline TP4056 & 1 & Battery charger \\
\hline 18650 Lanzhd & 1 & Li-Ion battery 2600 mAh \\
\hline Micro SD TF Card Memory & 1 & Micro SD module \\
\hline A scheme, developed in Frizing & with & the final design included \\
\hline
\end{tabular}

A scheme, developed in Fritzing, with the final design included all the components integrated into the assembly is shown in figure 1.

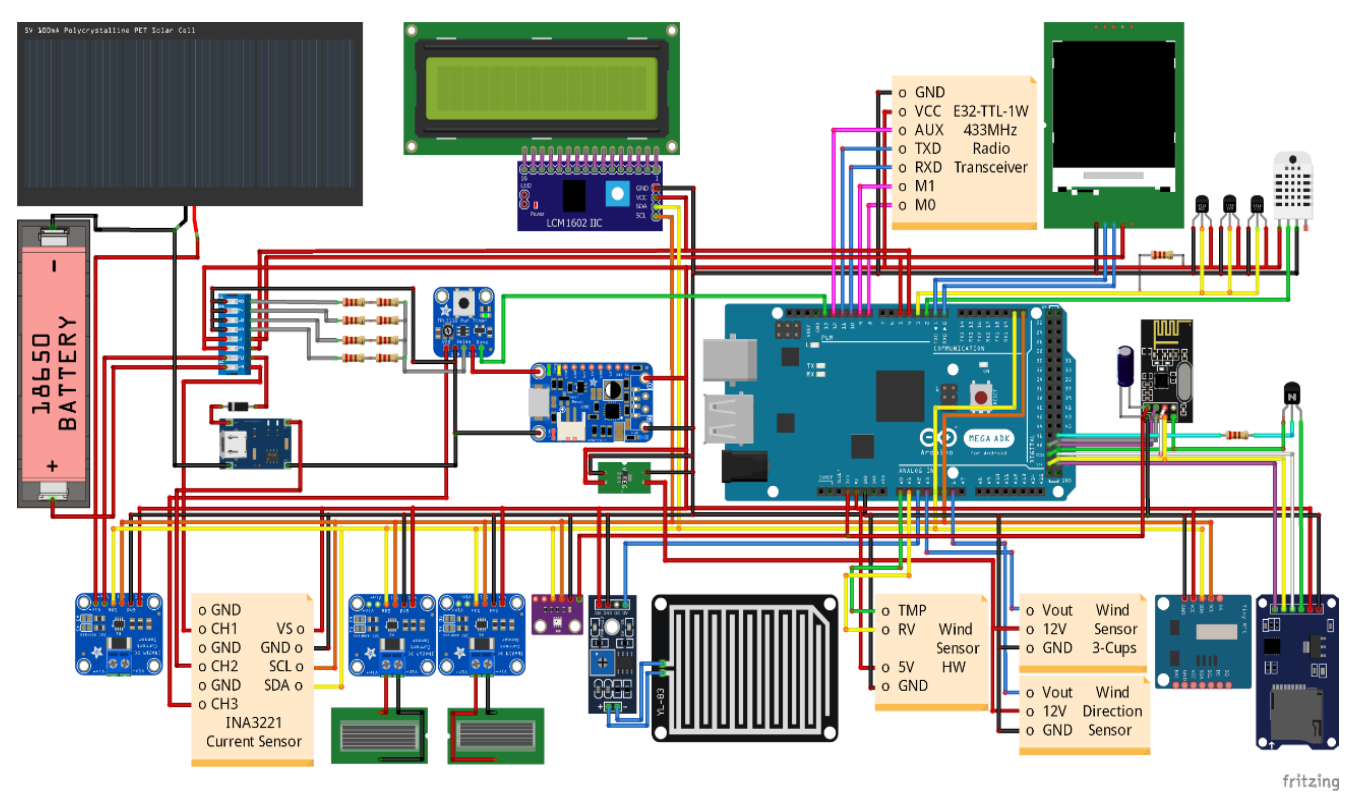

Figure 1. Scheme with the final design of the prototype developed in Fritzing. Source: fritzing (2019)

To integrate all the sensors in the Arduino board, a PBC board was designed and printed. For such purpose, the easyeda platform was used. The design obtained is shown in figure 
2a. A picture of the PCB board with all the connectors and some sensors is shown in figures $2 \mathrm{~b}$ and $2 \mathrm{c}$.

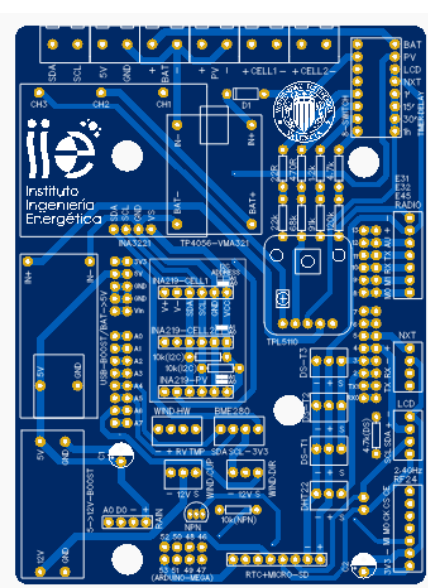

(a)

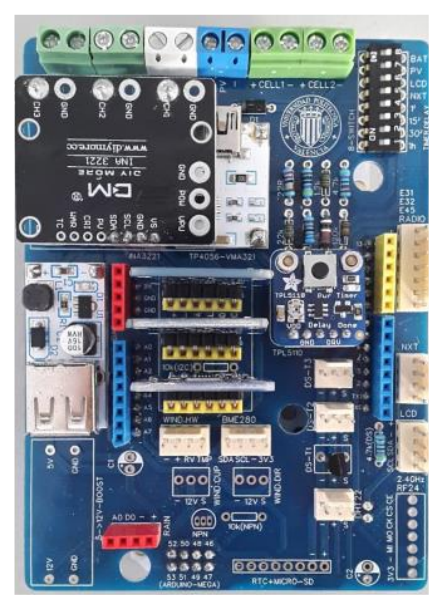

(b)

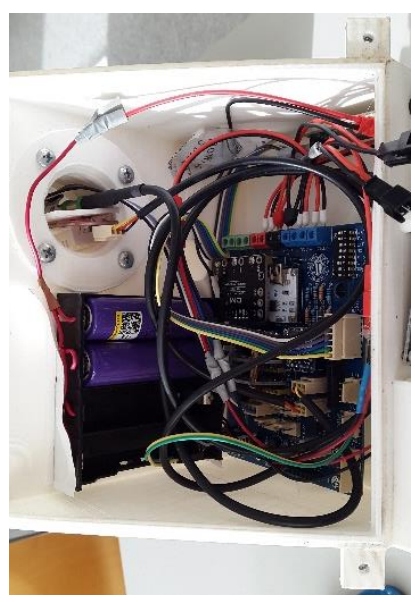

(c)

Figure 2. PCB design used easyeda. Board printed (a). Board with some components integrated ( $b, c)$

Once the designed was carried out, the Arduino board is programmed. The program uses the libraries recommended by the manufactures of the sensors. The libraries used for programming the Arduino board are shown in figure 3.

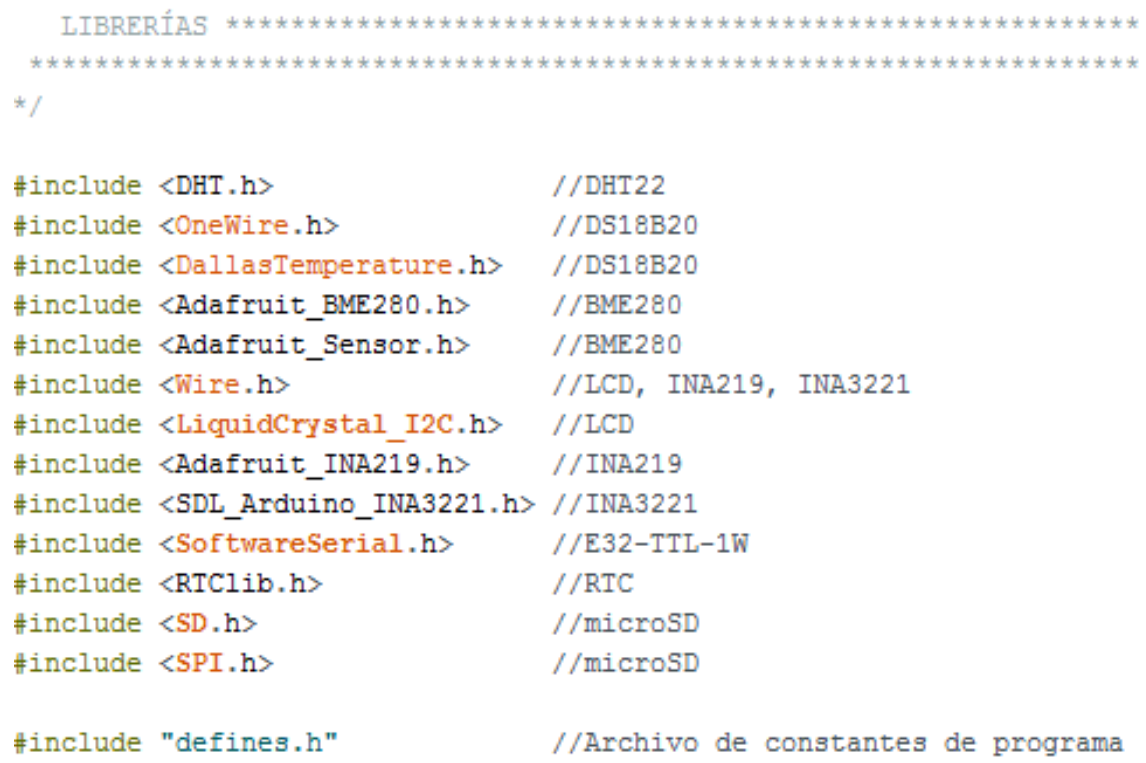

Figure 3. Libraries used in the Arduino code. Source: Arduino (2019) 
One of the components of the system is a microSD card, used for storing all the data collected by the sensors. To save energy, the timer TPL5110 is in charge of running the program every 15 minutes to collect all the data from the sensors, when the data are stored into the microSD card, the program turns off the Arduino until the TPL5110 turn it on again after 15 minutes. The prototype does not require being connected to an $\mathrm{AC}$ power plug, since it has a PV panel which, by means of a charger, charges the 18650 battery, them, the system can continue operating at night.One part of the code used for programming the Arduino board is shown in figure 4.

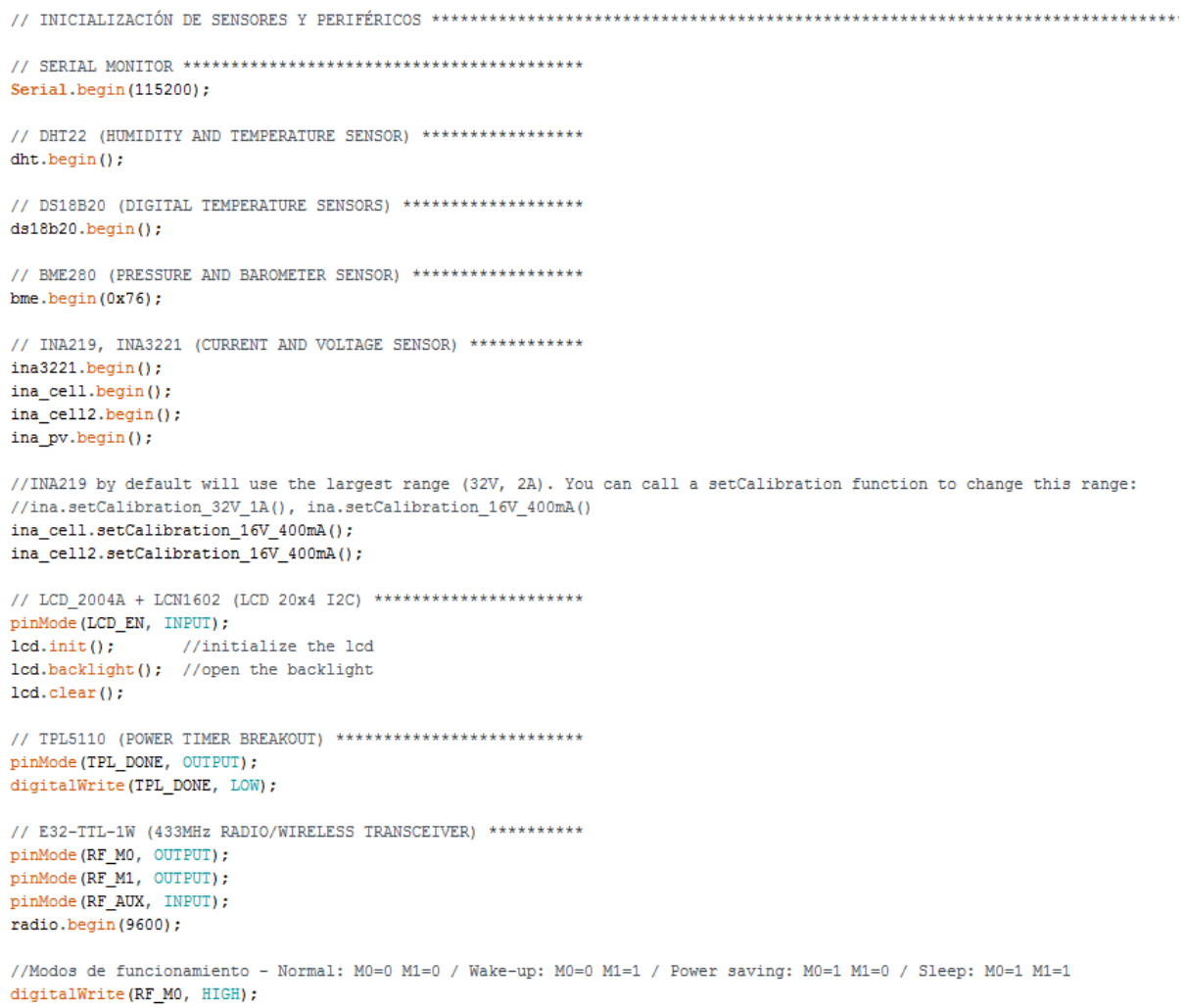

Figure 4. Part of the code used for programming the Arduino board Arduino (2019)

Once the prototype has been assembled and tested, it was required to design a box for the prototype. Figure 5 shows the box designed in a 3D printer by means of the tinkercad platform. Figure 6 shows a picture of the final box and its components. 

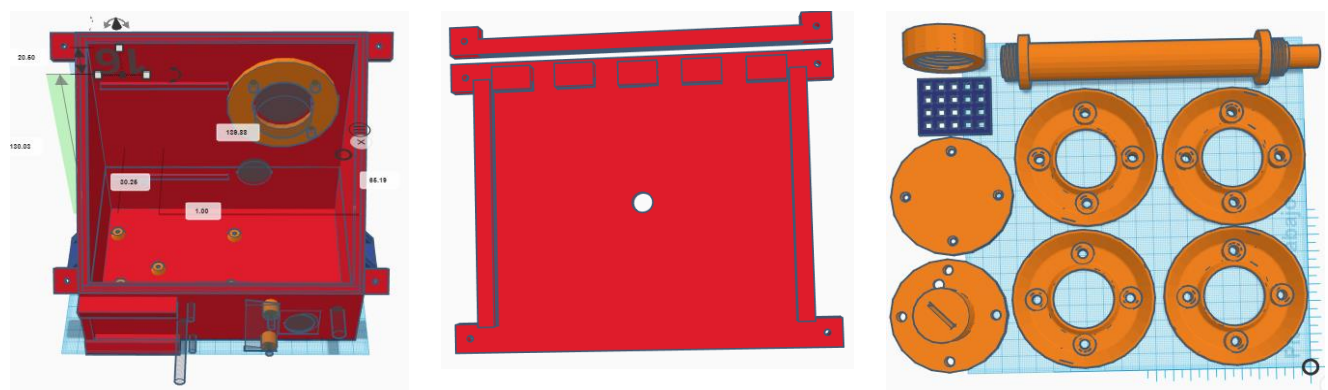

Figre 5. Prototype box designed for the assembly. Surce: tinkercad (2019)
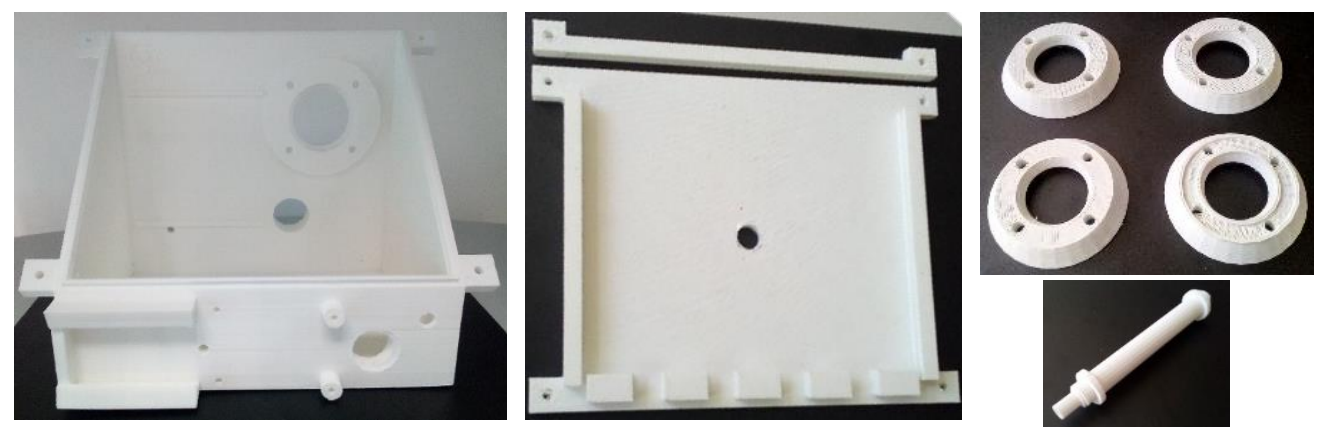

Figure 6. Printed parts of the prototype box

According to NTP 322, WBGT index calculation for outdoor (with solar irradiance) environments is carried out by Equation 1.

$$
W B G T_{\text {outdoor }}=0.7 t_{n w b}+0.2 t_{g}+0.1 t_{a} \quad \text { Equation } 1
$$

Mean radiant temperature (MRT) $\bar{t}_{r}$ is calculated according to (UNE ISO 7726, 2002) using Equations 2. (For forced convection when globe diameter is equal to $15 \mathrm{~cm}$ ). $\bar{t}_{r}$ depend on the globe temperature $t_{g}$, the wind velocity $v_{\text {wind }}$, and the air temperature $t_{a}$.

$$
\bar{t}_{r}=\left[\left(t_{g}+273\right)^{4}+2.5 x 10^{8} x\left(v_{\text {wind }}\right)^{0.6}\left(t_{g}-t_{a}\right)\right]^{1 / 4}-273 \quad \text { Equation } 2
$$




\section{Results}

As a result, a device able to monitoring heat stress indices was obtained. The final design is shown in figure 7.
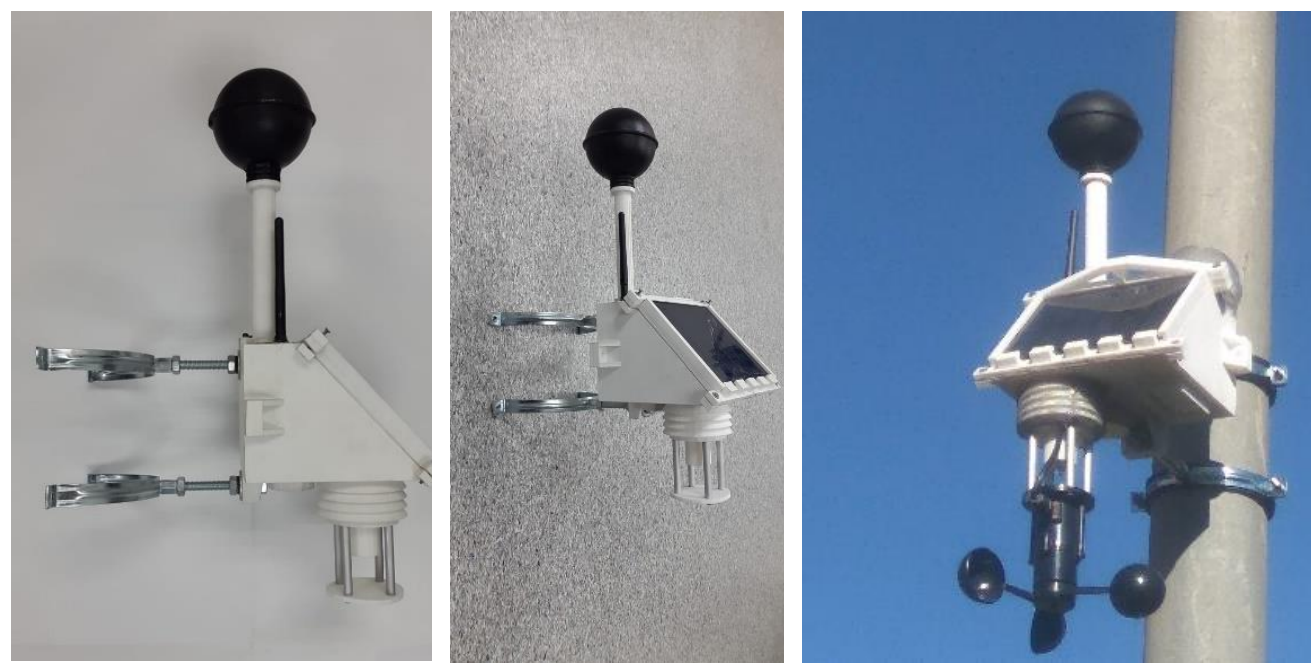

Figure 7. Prototype final design

Data are collated and exported to an excel file to be processed. An example of the data obtained are shown in table 2 .

Table 2. Data collected from the microSD card

\begin{tabular}{ccccccccc}
\hline Date & HR \% & $\begin{array}{c}\text { Ta } \\
\left({ }^{\circ} \mathbf{C}\right)\end{array}$ & Tbox $\left(\mathbf{C}^{\circ}\right)$ & $\begin{array}{c}\text { Tg } \\
\left({ }^{\circ} \mathbf{C}\right)\end{array}$ & Patm $(\mathbf{P a})$ & IRR $\left(\mathbf{W} / \mathbf{m}^{2}\right)$ & RAIN & Vwind (m/s) \\
\hline $13 / 02 / 201918: 30$ & 71,36 & 13,8 & 13,61 & 15,4 & 103155 & 3,33 & 0 & 0,43 \\
$13 / 02 / 201918: 45$ & 73,34 & 13,52 & 13,24 & 14,21 & 103097 & 0,83 & 0 & 0,84 \\
$13 / 02 / 201919: 00$ & 73,99 & 13,4 & 13,06 & 13,39 & 103115 & 0,38 & 0 & 0,88 \\
$13 / 02 / 201919: 15$ & 76,48 & 13,3 & 12,93 & 12,89 & 103131 & 0,31 & 0 & 0,66 \\
$13 / 02 / 201919: 45$ & 77,38 & 13,19 & 12,8 & 12,55 & 103155 & 0,31 & 0 & 1,32 \\
$13 / 02 / 201920: 00$ & 77,11 & 13,05 & 12,62 & 12,37 & 103158 & 0,34 & 0 & 0,21 \\
$13 / 02 / 201920: 15$ & 81,08 & 13,06 & 12,61 & 12,19 & 103167 & 0,31 & 0 & 0,55 \\
$13 / 02 / 201920: 30$ & 81,24 & 13 & 12,56 & 12,13 & 103180 & 0,34 & 0 & 0,74 \\
$13 / 02 / 201920: 45$ & 83,36 & 12,9 & 12,49 & 12,08 & 103189 & 0,31 & 0 & 0,46 \\
$13 / 02 / 201921: 00$ & 84,17 & 12,69 & 12,25 & 12,01 & 103206 & 0,31 & 0 & 0,34
\end{tabular}


Arduino-based prototype to estimate heat stress indices in urban environments

$\begin{array}{lllllllll}13 / 02 / 201921: 15 & 85,95 & 12,42 & 12,05 & 11,81 & 103216 & 0,31 & 0 & 0,44 \\ 13 / 02 / 201921: 30 & 83,96 & 12,3 & 11,87 & 11,55 & 103214 & 0,38 & 0 & 0,22\end{array}$

The device has been tested since February 2019, but due to the big amount of collated data, to analyze the results, 15 th and 17 th of February were chosen.

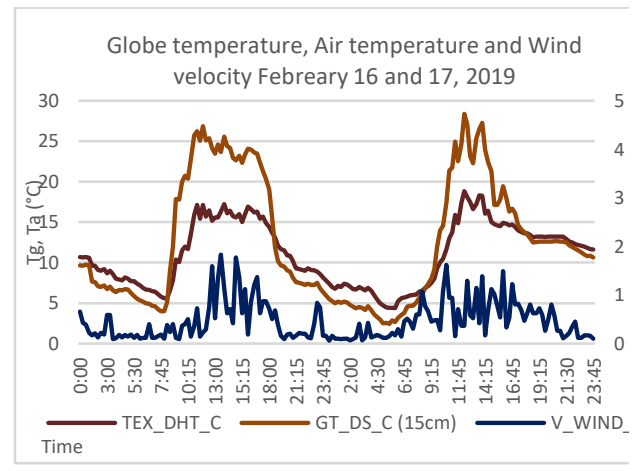

(a)

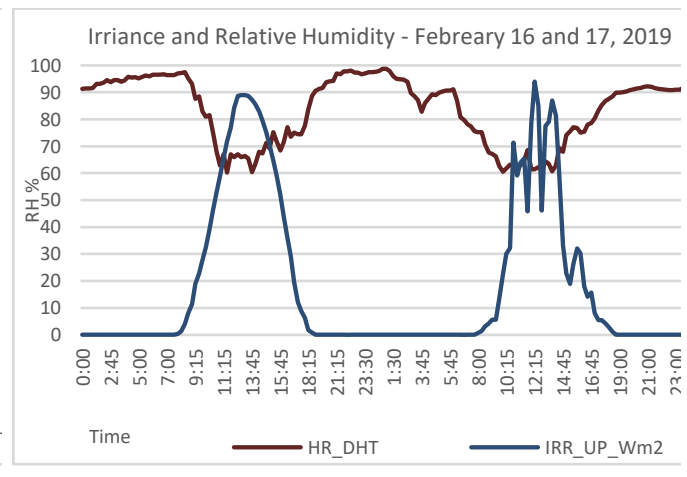

(b)

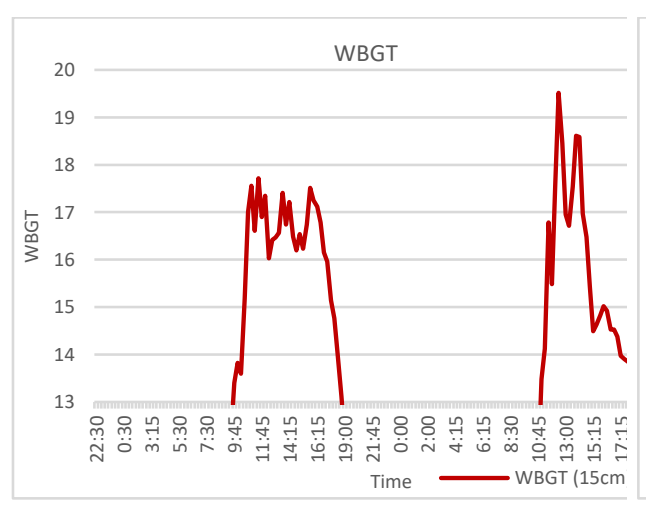

(c)

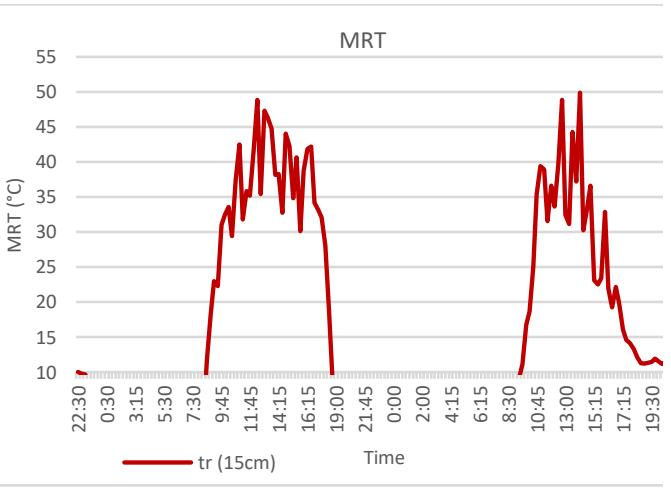

(d)

Figure 8. Collected data on February 16 and 17, 2019. Air temperature, Globe temperature and wind velocity (A), relative humidity and solar irradiance $(b), W B G T(c)$ and $M R T(d)$

The designed prototype is able to measure continuously parameters such as Air temperature, Globe temperature, wind velocity, relative humidity, solar irradiance and atmospheric pressure (figure $8 \mathrm{a}$ and $8 \mathrm{~b}$ ). By means of the parameters measured it is possible to calculate heat stress indices such as WBGT and RMT (figures 8c and 8d). 


\section{Conclusion and discussion}

Using the prototype designed and tested, two of the most important heat stress indices were calculated: WBGT and RMT. The values obtained let asses the level of heat stress in the areas under study. Knowing the level of heat stress, measures could be taken to alleviate it and improve the quality of life of the people affected. Depending on the results obtained by the prototype, some of the measures to mitigate heat stress are the installation of green facades, green roof, and tree planting. After setting up such components, by mean of the device designed, it is possible the quantification of the effect due to the improvements carried out.

\section{Acknowledgements}

This work was supported by European Commission through GROW GREEN project (Agreement number: 730283 — GROW GREEN - H2020-SCC-2016-2017/H2020-SCCNBS-2stage-2016. http://growgreenproject.eu/)

This work was supported in part by the regional public administration of Valencia under the grant ACIF/2018/106.

\section{References}

Arduino (2019) [Software]. Recuperado de https://www.arduino.cc/en/main/software

A. D. Deshmukh and U. B. Shinde, "A low cost environment monitoring system using raspberry Pi and arduino with Zigbee," in 2016 International Conference on Inventive Computation Technologies (ICICT), 2016, pp. 1-6.

Deschenes, O. (2014). Temperature, human health, and adaptation: A review of the empirical literature. Energy Economics, 46, 606-619. https://doi.org/10.1016/j.eneco.2013.10.013

Enander, A. E., \& Hygge, S. (1990). Thermal stress and human performance. Scandinavian Journal of Work, Environment and Health, 16(SUPPL. 1), 44-50. https://doi.org/10.5271/sjweh.1823

Fishman, R., Carrillo, P., \& Russ, J. (2019). Long-term impacts of exposure to high temperatures on human capital and economic productivity. Journal of Environmental Economics and Management, 93, 221-238. https://doi.org/10.1016/j.jeem.2018.10.001

Gasparrini, A., Guo, Y., Sera, F., Vicedo-Cabrera, A. M., Huber, V., Tong, S., ... Armstrong, B. (2017). Projections of temperature-related excess mortality under climate change scenarios. The Lancet Planetary Health, 1(9), e360-e367. https://doi.org/10.1016/S2542-5196(17)30156-0

Fritzing (2019) [Software]. Recuperado de http://fritzing.org/home/ 
Gunawardena, K. R., Wells, M. J., \& Kershaw, T. (2017). Utilising green and bluespace to mitigate urban heat island intensity. Science of the Total Environment, 584-585, 1040 1055. https://doi.org/10.1016/j.scitotenv.2017.01.158

I. Allafi and T. Iqbal, "Low-Cost SCADA System Using Arduino and Reliance SCADA for a Stand-Alone Photovoltaic System,” J. Sol. Energy, vol. 2018, pp. 1-8, 2018.

J. L. Sarinda, T. Iqbal, and G. Mann, (2017) "Low-cost and open source SCADA options for remote control and monitoring of inverters," Can. Conf. Electr. Comput. Eng.,.

Maurya, P. K., Haque, N., Kumar, R., \& Diwakar, R. (2019). SELECTING A SUITABLE HEAT STRESS INDEX TO PROTECT CATTLE AND, (March), 18-21.

V. H. Nguyen, Q. T. Tran, and Y. Besanger, "SCADA as a service approach for interoperability of micro-grid platforms," Sustain. Energy, Grids Networks, vol. 8, pp. 26-36, Dec. 2016.

S. Ferdoush and X. Li, "Wireless Sensor Network System Design Using Raspberry Pi and Arduino for Environmental Monitoring Applications," Procedia Comput. Sci., vol. 34, pp. 103-110, Jan. 2014.

Tinkercad (2019) [Software]. Recuperado de https://www.tinkercad.com/dashboard 